\title{
PERBANDINGAN HASIL ANALISIS METODE ELEMEN HINGGA BERBASIS SOFTWARE DENGAN SIMPLE SUPPORTED CALCULATION PADA KAPAL 50 PAX CRANE BARGE
}

\author{
Meida Perwira Antartika*, Budianto ${ }^{\#}$, Muhamad Ari" ${ }^{\#}$ Ketut Suastika ${ }^{2 \#}$ \\ * Politeknik Negeri Batam \\ Jurusan Teknik Mesin \\ Jalan Ahmad Yani, Batam Centre, Batam 29461, Indonesia \\ E-mail: meidaperwira@polibatam.ac.id \\ \# Politeknik Perkapalan Negeri Surabaya \\ Jurusan Teknik Bangunan Kapal \\ 2\# Institut Teknologi Sepuluh Nopember, Surabaya \\ Prodi Teknik Perkapalan
}

\begin{abstract}
Abstrak
Metode Elemen Hingga untuk analisis kekuatan suatu struktur semakin populer. Metode analisis tersebut pada umumnya dipermudah dengan menggunakan software. Pada penelitian ini dianalisis suatu struktur kostruksi forward storage platform pada kapal 50 PAX Crane Barge. Struktur pada kapal ini menggunakan BV grade A steel. Profil pada konstruksi forward storage platform ini, struktur menahan beban sebesar 6,4 ton (3,2 ton portside dan 3,2 ton startboard). Kondisi beban dianggap dalam kondisi statis, dinamis, dan impact. Struktur pada kosntruksi forward storage platform menggunakan profil L $75 \times 75 \times 6$ sebagai penguat utama, masingmasing berjarak $1829 \mathrm{~mm}$. penguat utama ini terhubung dengan pelat, dan berfungi sebagai penyangga utama beban yang akan diberikan. Hasil Analisis menggunakan software berupa von Mises stress, normal stress, dan principal stress. Sebagai verifikasi, dilakukan perhitungan manual menggunakan metode Simple Supported Calculation. Pada penelitian ini membandingkan von Mises stress, normal stress, dan principal stress hasil Metode Elemen Hingga dengan stress hasil Simple Supported Calculation.
\end{abstract}

Kata kunci: Metode elemen hingga, tongkang, perhitungan mekanika sederhana

\begin{abstract}
The Finite Element Method for the analysis of the strength of a structure is increasingly popular. The method of analysis is easy by using software. In this study an storage platform structure was analyzed on the 50 PAX Crane Barge vessel. The structure of this vessel uses BV grade A steel. Profile in this forward storage construction platform, the structure withstand loads is 6.4 tons (3.2 tons portside and 3.2 tons startboard). Load conditions are considered to be static, dynamic and impact conditions. The structure of the forward storage platform uses the $75 \times 75 \times 6 \mathrm{~L}$ profile as the main beam each $1829 \mathrm{~mm}$ apart. This main beam is connected to the plate, and functions as the distribution of the load. The results of the analysis using software is von Mises stress, normal stress, and principal stress. As a verification using the Simple Supported Calculation method. In this study comparing von Mises stress, normal stress, and principal stress results of the Finite Element Method with stress results of Simple Supported Calculation.
\end{abstract}

Keywords: Finite Element Method, Barge, Simple Supported Calculation 


\section{Pendahuluan}

PT. Y merupakan perusahaan yang bergerak di bidang konsultan untuk pekerjaan kelautan dan perkapalan. Perusahaan tersebut menyediakan jasa pembuatan desain dan pemodelan kapal baru maupun konversi dan struktur lepas pantai untuk mitra kerja perusahaan. Salah satu mitra kerja perusahaan meminta untuk membat desain forward storage platform pada kapal 50 PAX crane barge.

Desain forward storage platform harus mampu menahan beban sebesar 6,4 ton pada kapal 50 pax crane barge. Beban tersebut berasal dari wirerope dan perlengkapannya. Struktur yang digunakan dalam membuat desain forward storage platform yaitu chequered plate $(914 \times 1829)$ sebagai pelat penahan, angle bar (L 75x75x6 dan L 50x50x6) sebagai penguat, dan flat bar (32x8) sebagai sekat antar pelat. Akan diberi beban sebesar 6 ton untuk kedua kompartemen forward storage platform.

Dalam proses desain konstruksi kapal harus sesuai dengan rules atau klasifikasi yang sudah diakui di dunia perkapalan internasional, sedangkan dalam proses desain storage platform ini mengacu pada gambar referensi pada kapal lain. Dalam proses desain tersebut aturan bentuk bentuk desain dan perhitungannya tidak ada di rules atau klasifikasi, sehingga perlu dilakukan analisis. Sedangkan untuk ketentuan mechanical properties material tetap mengacu pada rules. Pada pembuatan kapal 50 PAX crane barge ini yaitu BV (Bureau Veritas) rules.

Pada penelitian ini dilakukan analisis untuk desain konstruksi forward storage platform pada kapal 50 PAX crane barge. Analisis ini dengan pengkondisian beban statis, dinamis, dan impak. Analisis ini dibantu software berbasis Metode Elemen Hingga. Metode ini bertujuan untuk mengetahui nilai von Mises stress, normal stress, dan principal stress.

Dengan Metode Elemen Hingga dapat diketahui nilai von Mises stress, normal stress, dan principal stress dalam kondisi statis, dinamis, dan impact. Hasil dari Metode Elemen Hingga untuk tiga jenis tegangan tersebut dikomparasi dengan hasil dari Simple Supported Calculation.

\section{Dasar Teori}

\subsection{Macam-macam Beban}

Adapun secara sederhana pengelompokan beban yang bekerja dapat disebut beban statis, beban dinamis, dan tumbukan. Beban Statis adalah beban yang berubah apabila berat total kapal berubah, sebagai akibat kegiatan bongkar muat, pemakaian bahan bakar atau perubahan pada kapal itu sendiri. Pembebanan statis merupakan jenis pembebanan yang bersifat tetap [11]. Yang dianggap untuk beban ini adalah beban wireropes dan shackles dengan asumsi besarnya tidak berubah.

Beban Dinamis adalah beban yang besarnya berubah terhadap waktu dengan frekuensi tertentu yang menimbulkan respon berupa getaran terhadap struktur kapal. Dalam penelitian ini adalah beban wireropes ketika kapal dalam keadaan bergerak, sehingga menimbulkan getaran pada wireropes yang direspon oleh struktur kapal. Sehingga untuk mengetahui beban dinamis maka pendekatan dilakukan dengan menambahkan dynamic amplification total yaitu beban dikalikan dengan 1,3.

Beban impact (tumbuk) merupakan beban yang terjadi akibat pukulan pada satu struktur. Dalam penelitian ini yang dimaksud dengan beban tumbuk yaitu diasumsikan wireropes dan shackle di forward storage platform jatuh dari ketinggian. Hal bisa terjadi disebabkan berbagai faktor. Pendekatan nilai beban tumbuk dapat dilakukan dengan cara beban statis dikalikan dengan faktor impact.

$$
n=1+\sqrt{ }(1+2 h / \delta)
$$

\subsection{Tegangan}

Tegangan yang terjadi pada struktur konstruksi forward storage platform pada kapal 50 PAX crane barge ini akibat dari beban merata, pendekatan beban merata dapat dilihat pada gambar dibawah ini.

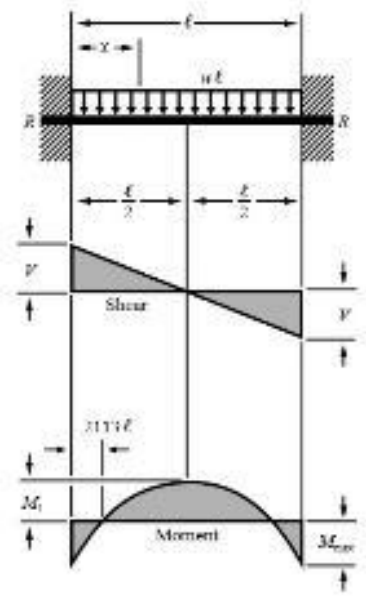

Gambar 1. Beban Merata

Sumber :
https://www.linsgroup.com/MECHANICAL_DESIGN/Beam/beam_formula.htm

Gambar 1 diformulasikan yaitu sebagai berikut.

$$
\mathrm{M}_{\max }=\frac{1}{12} \mathrm{q} \ell^{2}
$$

Momen tersebut digunakan untuk menghitung nilai tegangan dengan formula sebagai berikut.

$$
\sigma=\mathrm{M} \cdot \mathrm{y} / \mathrm{I}_{\mathrm{xx}}
$$

Tegangan merupakan Momen dikalikan dengan jarak titik pusat penampang terhadap sumbu y dan dibagi dengan momen inersia penampang pada sumbu x. Dengan kata lain, tegangan adalah suatu ukuran intensitas pembebanan yang dinyatakan oleh gaya dibagi oleh luas di tempat gaya tersebut bekerja. Komponen tegangan pada sudut yang tegak lurus pada bidang ditempat bekerjanya gaya tersebut disebut tegangan langsung, dan merupakan tegangan tarik atau tensile (positif), atau tegangan tekan atau compressive (negatif). Satuan untuk tegangan tersebut adalah $\mathrm{N} / \mathrm{mm}^{2}$ [9]. 
Regangan (elongation) adalah suatu bentuk tanpa dimensi untuk menyatakan perubahan bentuk (deformasi).

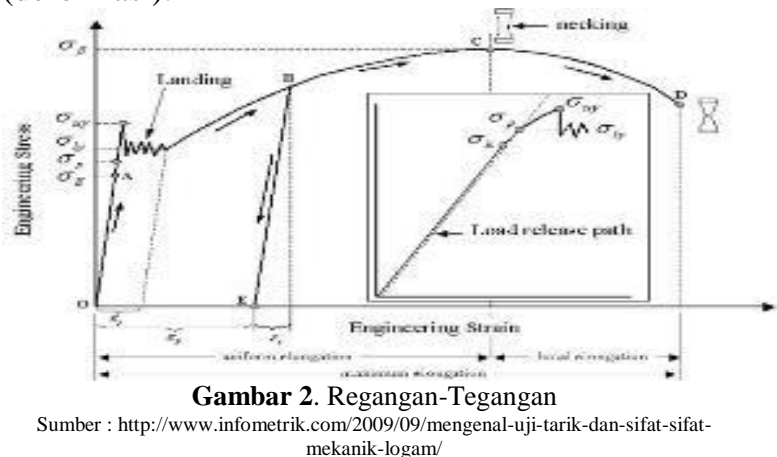

Tegangan luluh bawah $\sigma_{\text {ly }}$ (lower yield strength) merupakan tegangan pada daerah landing sebelum memasuki fase deformasi plastis. Bila hanya disebutkan tegangan luluh (yield stress), maka yang dimaksud adalah tegangan ini.

Tegangan tarik maksimum (ultimate tensile strength) pada gambar 2, ditunjukkan dengan titik C $(\sigma \beta)$, merupakan besar tegangan maksimum yang didapatkan dalam uji tarik. Pada posisi ini material mengalami patah.

Regangan luluh ey (yield strain) Regangan permanen saat bahan akan memasuki fase deformasi plastis. Regangan elastis $\varepsilon_{\mathrm{e}}$ (elastic strain) Regangan yang diakibatkan perubahan elastis bahan. Pada saat beban dilepaskan, bentuk material akan kembali ke posisi semula. Regangan plastis $\varepsilon_{\mathrm{p}}$ (plastic strain) Regangan yang diakibatkan perubahan plastis. Pada saat beban dilepaskan, material tidak dapat kembali pada bentuk seperti semula.

Tegangan normal adalah tegangan yang terjadi ketika gaya yang diterapkan tegak lurus terhadap luas penampang material. Principal stress adalah nilai ekstrim dari tegangan normal yang terjadi pada material. Jika diibaratkan sebuah kubus, arah tegangannya searah dengan permukaan kubus, dan mengabaikan tegangan geser. Von Mises stress adalah resultan dari semua tegangan yang terjadi diturunkan dari principal axes dan berhubungan dengan principal stress stress [17].

\subsection{Material}

Pada penelitian ini konstruksi yang dianalisis menggunakan material BV grade A steel yang mempunyai machanical properties sebagai berikut.

\begin{tabular}{|l|c|l|l|}
\multicolumn{5}{|c|}{ Tabel 1. Mechanical Properties } \\
\hline $\begin{array}{c}\text { Steel } \\
\text { grade }\end{array}$ & $\begin{array}{c}\text { Yield } \\
\text { Stress } \\
\left(\mathrm{N} / \mathrm{mm}^{2}\right) \text { min. }\end{array}$ & $\begin{array}{c}\text { Tensile } \\
\text { Strength } \\
\left(\mathrm{N} / \mathrm{mm}^{2}\right)\end{array}$ & $\begin{array}{c}\text { Elongatio } \\
n \\
(\%)\end{array}$ \\
\hline $\mathrm{A}$ & 235 & $400 / 520$ & 22 \\
\hline $\mathrm{B}$ & 235 & $400 / 520$ & 22 \\
\hline $\mathrm{D}$ & 235 & $400 / 520$ & 22 \\
\hline $\mathrm{E}$ & 235 & $400 / 520$ & 22 \\
\hline
\end{tabular}

Material pada tabel di atas merupakan material standar marine untuk hull structures. Yang digunakan dalam pembuatan forward storage platform yaitu grade A steel yang mempunyai yield strength $235 \mathrm{~N} / \mathrm{mm}^{2}$. Dalam penelitian ini, pada tabel 1 yang perlu diperhatikan adalah yield strenght, karena yang digunakan sebagai acuan batas tegangan hasil analisis.

Jadi untuk membuat struktur tetap berada dalam suatu keadaan elastis dan mencegah setiap kemungkinan terjadinya keadaan permanen, biasanya tegangan kerja dibuat jauh berada di bawah batas proporsional ini diperlukan alat-alat ukur yang peka (extensometer), sebab letak batas ini sebagian tergantung kepada ketepatan pengukuran. Untuk menghindari kesukaran ini biasanya titik lumer dan kekuatan maksimum bahan dijadikan sebagai dasar untuk menentukan besarnya tegangan kerja [14].

\section{Metodologi}

Metode pada penelitian menggunakan Metode Elemen Hingga, untuk memudahkan maka dikerjakan dengan bantuan software. Dari analisis menggunakan Metode Elemen Hingga tersebut akan dikomparasikan dengan Simple Supported Calculation menggunakan formula-formula yang ada di bab 2. Simple Supported Calculation merupakan pendekatan untuk mengetahui besar tegangan pada suaatu struktur.

Secara garis besar langkah analisis menggunakan Metode Elemen Hingga dengan bantuan software yaitu membuat model, menentukan jenis studi, menentukan jenis material, menentukan beban, menentukan kondisi batas, meshing, dan analisis.

Pemodelan desain yang akan dianalisis yaitu memodelkan gambar desain menjadi model 3D.

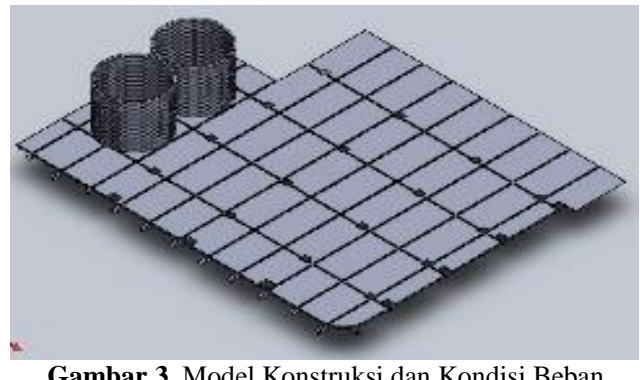

Struktur yang dimodelkan cukup desain forward storage platform. Karena pemodelan yang dibuat dalam bentuk tiga dimensi, maka solid mesh merupakan tipe meshing yang dianjurkan. Meshing yang digunakan pada penelitian ini adalah fine mesh agar hasilnya akurat.

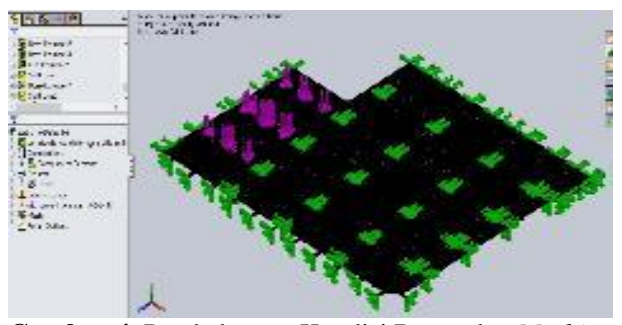

Gambar 4. Pembebanan, Kondisi Batas, dan Meshing 
Jenis analisis pada penelitian ini yaitu statis, dinamis, dan tumbukan. Struktur konstruksi forward storage platform ini dilas dengan struktur lainnya, sehingga jenis kondisi batasnya berupa fix.

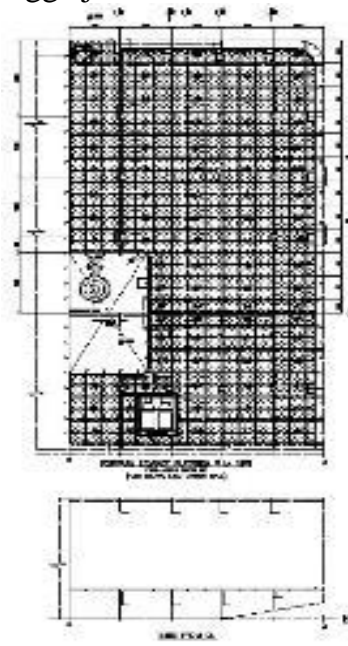

Gambar 5. Boundary Condition Forward Storage Platform

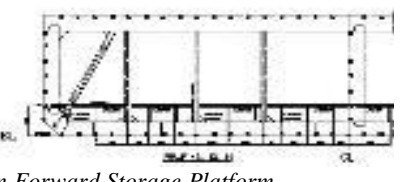

Bagian yang terhubung dengan struktur lain yaitu penguat utama. Sebelum running analisis perlu dipastikan bahwa input besaran dan asumsi jenis beban sudah mendekati kasus sebenarnya. Material yang digunakan adalah BV grade A steel. Pada langkah ini memasukkan mechanical properties sesuai dengan tabel 1. Kemudia running analisis dengan simulasi beban statis, dinamis, dan impak.

Ketika Metode Elemen Hingga diterapkan untuk bidang analisis tertentu (seperti analisis stres, analisis termal, atau analisis getaran) sering disebut sebagai analisis elemen terbatas (FEA). Sehingga FEA adalah alat yang paling umum untuk menganalisis stres dan analisis struktur [1].

\section{Analisis dan Pembahasan}

Beban statis yang menimpa pada rangkaian struktur untuk konstruksi forward storage platform yaitu sebesar 6,4 ton pada dua kompartemen. Forward storage pada kapal ini dibagi dua kompartemen pada portside dan startboard.

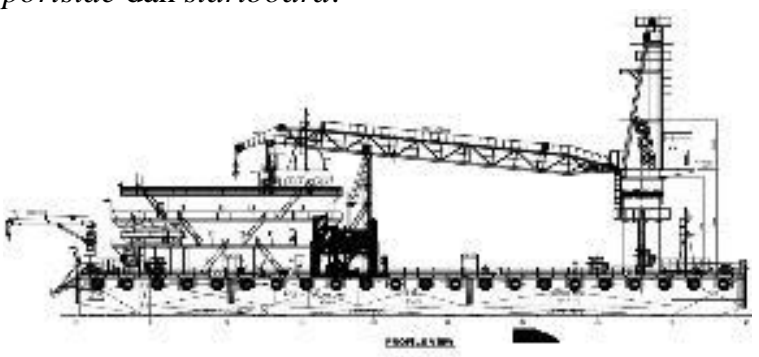

Gambar 6. General Arrangement 50 PAX Crane Barge

Melihat di arrangement pada kapal ini, posisi towing ada di portside dan startboard, sehingga beban wirerope dan komponen lainnta 3,2 ton di portside dan 3,2 ton di startboard. Data di dalam technical spesification yang diberi oleh galangan memberikan keterangan bahwa forward storage compartement akan diisi dengan wireropes serta kelengkapannya, biasanya shackle. Wireropes berfungsi sebagai tali ketika kapal sedang mooring atau tambat di tengah dilaut.

Analisis konstruksi forward storage platform dikondisikan dengan tiga jenis beban, yaitu statis, dinamis, dan impak. Hasil analisis menggunakan Metode Elemen Hingga berupa von Mises stress, normal stress, dan principal stress. Untuk Simple Supported Calculation, akan menghasilkan nilai tegangan yang akan dikomparasi dengan von Mises stress, normal stress, dan principal stress.

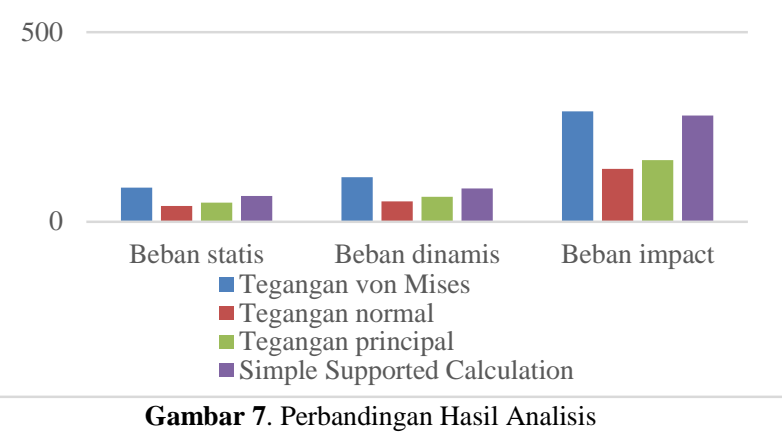

Penjelasan grafik dalam gambar 7 dijelaskan pada bab 4.1 hasil analisis von Mises stress, bab 4.2 hasil analisis normal stress, dan 4.3 hasil analisis principal stress.

\subsection{Analisis Von Mises Stress}

Analisis menggunakan Metode Elemen Hingga. Besarnya von Mises stress yang terjadi pada konstruksi forward storage platform pada kapal 50 $P A X$ crane barge untuk setiap kondisi pembebanan yaitu beban statis, beban dinamis, dan beban impact.

Pembebanan statis merupakan jenis pembebanan yang bersifat tetap (tidak ada gerakan maupun getaran), dalam hal ini adalah pembebanan wireropes dan komponen lainnya dengan asumsi besarnya tidak berubah. Sedangkan pembebananan dinamis diasumsikan beban mengalami gerakan atau getaran. Dan beban tumbukan yaitu beban mengalami tumbukan dengan struktur yang dianalisis.

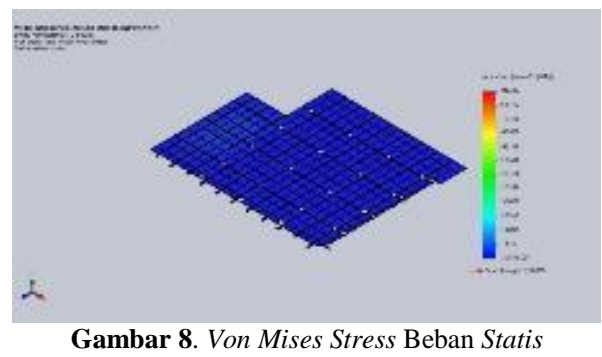

Dari gambar 8, menunjukkan hasil analisis menggunakan Metode Elemen Hingga. Dari hasil analisis tersebut diketahui bahwa von Mises stress maksimal yang terjadi sebesar 90,23 N/mm². Sedangkan menggunakan 
perhitungan manual Simple Supported Calculation sebesar $67,64 \mathrm{~N} / \mathrm{mm}^{2}$.

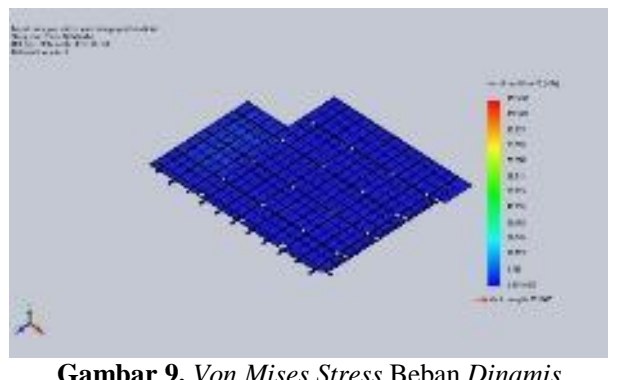

Dari gambar 9, menunjukkan hasil analisis menggunakan Metode Elemen Hingga. Dari hasil analisis tersebut diketahui bahwa von Mises stress maksimal yang terjadi sebesar 117,45 N/mm². Sedangkan menggunakan perhitungan manual Simple Supported Calculation sebesar 87,94 N $\mathrm{N} / \mathrm{mm}^{2}$.

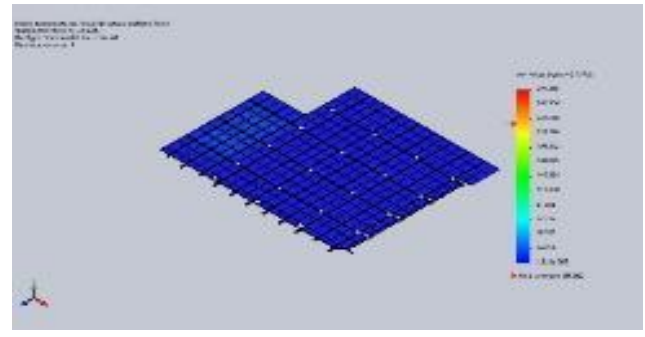

Gambar 10. Von Mises Stress Beban Impact

Dari gambar 10, menunjukkan hasil analisis menggunakan Metode Elemen Hingga. Dari hasil analisis tersebut diketahui bahwa von Mises stress maksimal yang terjadi sebesar 291,17 N/mm². Sedangkan menggunakan perhitungan manual Simple Supported Calculation sebesar 280,44 $\mathrm{N} / \mathrm{mm}^{2}$.

\subsection{Analisis Normal Stress}

Analisis menggunakan Metode Elemen Hingga. Besarnya normal stress yang terjadi pada konstruksi forward storage platform pada kapal 50 PAX crane barge untuk setiap kondisi pembebanan yaitu beban statis, beban dinamis, dan beban impact.

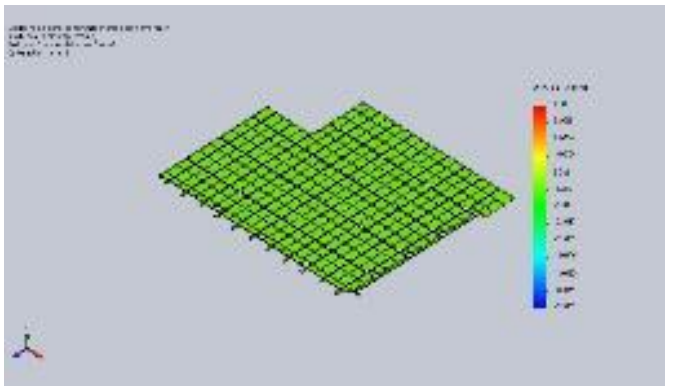

Gambar 11. Normal Stress Beban Statis

Dari gambar 11, menunjukkan hasil analisis menggunakan Metode Elemen Hingga. Dari hasil analisis tersebut diketahui bahwa normal stress maksimal yang terjadi sebesar 41,08 N/mm².
Sedangkan menggunakan perhitungan manual Simple Supported Calculation sebesar 67,64 N/mm².

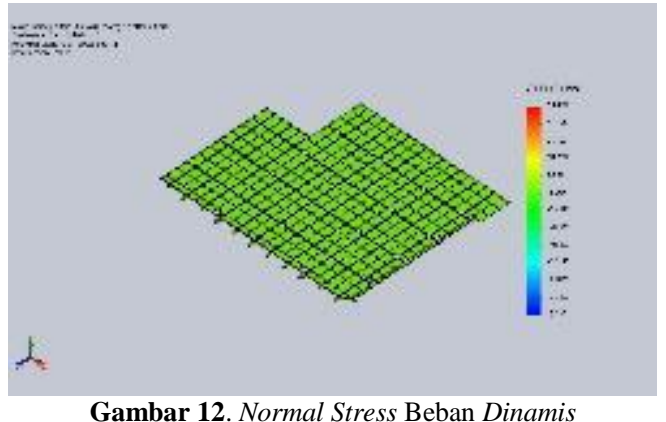

Dari gambar 12, menunjukkan hasil analisis menggunakan Metode Elemen Hingga. Dari hasil analisis tersebut diketahui bahwa normal stress maksimal yang terjadi sebesar $53,460 \mathrm{~N} / \mathrm{mm}^{2}$. Sedangkan menggunakan perhitungan manual Simple Supported Calculation sebesar 87,94 N $\mathrm{N} / \mathrm{mm}^{2}$.

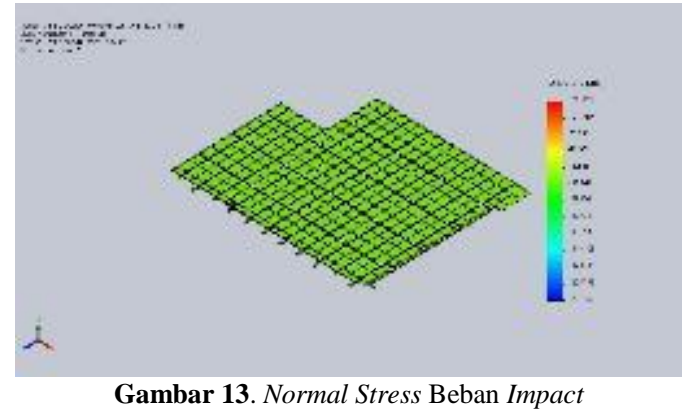

Dari gambar 13, menunjukkan hasil analisis menggunakan Metode Elemen Hingga. Dari hasil analisis tersebut diketahui bahwa normal stress maksimal yang terjadi sebesar 138,90 N/mm². Sedangkan menggunakan perhitungan manual Simple Supported Calculation sebesar 280,44 $\mathrm{N} / \mathrm{mm}^{2}$.

\subsection{Analisis Principal Stress}

Analisis menggunakan Metode Elemen Hingga. Besarnya normal stress yang terjadi pada konstruksi forward storage platform pada kapal 50 PAX crane barge untuk setiap kondisi pembebanan yaitu beban statis, beban dinamis, dan beban impact.

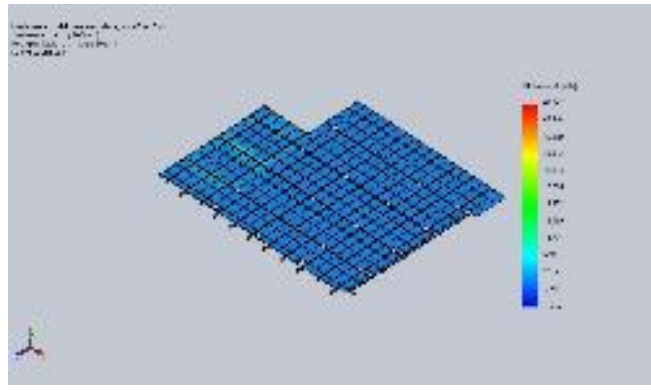

Gambar 14. Principal Stress Beban Statis

Dari gambar 14, menunjukkan hasil analisis menggunakan Metode Elemen Hingga. Dari hasil 
analisis tersebut diketahui bahwa principal stress maksimal yang terjadi sebesar 49,95 N/mm². Sedangkan menggunakan perhitungan manual Simple Supported Calculation sebesar 67,64 N/mm².

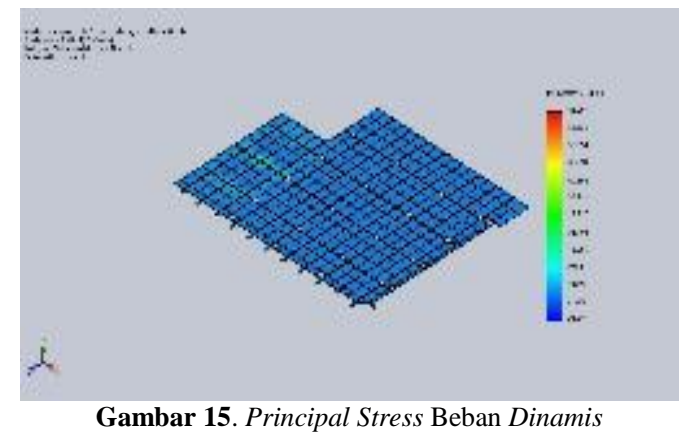

Dari gambar 15, menunjukkan hasil analisis menggunakan Metode Elemen Hingga. Dari hasil analisis tersebut diketahui bahwa principal stress maksimal yang terjadi sebesar 65,06 N/mm². Sedangkan menggunakan perhitungan manual Simple Supported Calculation sebesar 87,94 N $\mathrm{N} / \mathrm{mm}^{2}$.

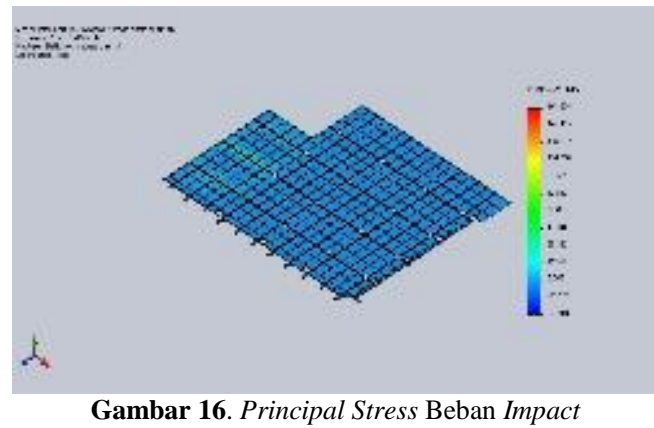

Dari gambar 16, menunjukkan hasil analisis menggunakan Metode Elemen Hingga. Dari hasil analisis tersebut diketahui bahwa principal stress maksimal yang terjadi sebesar 161,98 N/mm². Sedangkan menggunakan perhitungan manual Simple Supported Calculation sebesar 280,44 $\mathrm{N} / \mathrm{mm}^{2}$.

\section{Kesimpulan}

Pada penelitian ini membandingkan von Mises stress, normal stress, dan principal stress hasil Metode Elemen Hingga dengan stress hasil Simple Supported Calculation. Dari hasil analisis kekuatan forward storage platform menggunakan Simple Supported Calculation, pada analisis beban statis dan dinamis hasilnya mendekati hasil analisis Metode Elemen Hingga dengan bantuan software dengan selisih $25 \%$. Perlu studi lebih lanjut untuk mengetahui selisih yang lebih akurat antara hasil metode Simple Supported Calculation dengan hasil software.

\section{Daftar Pustaka}

[1] Akin, J. E. 2009. Finite Element Analysis Concepts via SolidWorks. Texas : Rice University Houston.

[2] American Wood Council. 2007. Beam Design Formulas with Sear and Moment Diagram. Washington DC : American Forest \& Paper Accosiation.

[3] Bernarthdus, I. 2015. "Stress, Strength, Safety". Tersedia : http://www. academia.edu.

[4] Budi, B. (2012). "Macam dan Jenis Kapal dalam Asuransi Rangka Kapal”. Tersedia : http://www. akademiasuransi.org.

[5] Bureau Veritas, 2011. Rules for the Certification of Lifting Appliances onboard Ships and Offshore Units. France : Marine \& Offshore Division 92571 Neuilly sur Seine Cedex.

[6] Bureau Veritas, 2014. Rules on Materials and Welding for the Classification of Marine Units. France : Marine \& Offshore Division 92571 Neuilly sur Seine Cedex.

[7] Engineering Analysis and Design Menu Engineering Design Consulting Services. "Factor of Safety Review". URL:http://www.engineersedge.com.

[8] Genc, M. 2001. The Impact of Immigration on International Trade:A Meta-Analysis. Bonn : Forschungsinstitut zur Zukunft der Arbeit Institute for the Study of Labor.

[9] Iremonger, M. J. 1990. Dasar Analisis Tegangan. Penerbit Universitas Indonesia (UIPress), Jakarta.

[10] Maljaars, J. 2002. Dynamic Increment Factor in Modular Expansion Joins of Bridges Under Heavy Traffic Loading. 7th International Symposium on Heavy Vehicle Weight \& Dimensions. Delft, The Netherlands, June 1620, 2002.

[11] Mulyanto, I. 2011. Analisa Kekuatan Konstruksi Car Deck pada Kapal KM. Dharma Ferry 3 dengan Metode Elemen Hingga. Kapal. Vol. 8, no. 2, Juni 2011.

[12] Popov, E.. 1996. Mechanics of materials. USA : Prentice Hall.

[13] Sukamto, E. 2014. Forward Storage Platform, No. Drawing 13-012-S-A1-AWB-B-24, No. Project D271 50 Pax Crane Barge. PT Marine Cadcam Indonesia, Batam. 
[14] Timoshenko, S. 1989. Dasar-dasar Perhitungan Kekuatan Bahan. Restu Jakarta : Restu Agung.

[15] Timoshenko, S. 2000. Mekanika Bahan. Jakarta : Erlangga.

[16] Sastranegara, A. 2009. "Mengenal Uji Tarik dan Sifat-sifat Mekanik Logam". Tersedia : http://www.infometrik. com.

[17] Singer, F. "Strength of Materials 4th Editon". Tersedia : http://www.comsizo.com. 